\title{
PET INTERDISCIPLINAR CONEXÕES DE SABERES: A TROCA DE CONHECIMENTOS NA EDUCAÇÃO BÁSICA CONSTRUINDO NOVOS CAMINHOS.
}

\author{
Jesus $\operatorname{Costa}^{1}$ \\ Thaís Pimentel ${ }^{2}$ \\ Maria José Rosário ${ }^{3}$
}

\begin{abstract}
RESUMO: No presente trabalho apresentaremos o recorte histórico das ações e resultados das atividades desenvolvidas pelo "Programa de Educação Tutorial - PET Interdisciplinar Conexões de Saberes: novo diálogo entre a UFPA e as Comunidades Populares" no período de 2010 até 2013 na Educação Básica, realizado na Escola Dr. Celso Malcher, localizada no bairro da Terra-Firme em Belém-Pa. O programa executa dois projetos de intervenção, sendo um o "Circuito de Leitura: lendo para ser feliz", que tem como objetivo aguçar nos educandos do fundamental II o prazer pela leitura e o outro "Conectando saberes" que buscar discutir os temas: Juventude e Educação; Ações Afirmativas; Direitos humanos e Acesso Permanência no Ensino superior Público que é realizado com os estudantes do Ensino Médio, além de tentar incentivar esse jovem a ingressar na Universidade Pública. Também será apresentada a metodologia utilizada no decorrer do trabalho e a conclusão.
\end{abstract}

PALAVRAS-CHAVE: Circuito de Leitura. Conectando Saberes. Temas Transversais.

\section{INTRODUÇÃO}

O Programa de Educação Tutorial como é conhecido atualmente desde 2004 com essa nomenclatura, foi criado em 1979 pela coordenação de aperfeiçoamento de Pessoal de Nível Superior-CAPES com o nome Programa Especial de treinamento-PET, que foi transferido no final de 1999 para a Secretaria de Educação Superior do Ministério da educação, tendo a sua gestão sob a responsabilidade do Departamento de modernização e Programas Superior- DEPEM (PROGRAMA DE EDUCAÇÃO TUTORIAL/MEC, 2006). A constituição dos grupos participantes desse programa se concretiza através de um professor tutor e um conjunto de discentes de graduação que tem como um de seus objetivos "[...] oportunizar aos estudantes participantes a possibilidade de ampliar a gama de experiências em sua formação acadêmica e cidadã" (IDEM, 2006).

\footnotetext{
${ }^{1}$ Estudante de filosofia, e-mail: iesuspcs20@yahoo.com.br; Universidade Federal do Pará;

${ }^{2}$ Voluntária; Universidade Federal do Pará; Belém, Pará; thaispimenta10@ hotmail.com;

${ }^{3}$ professora da UFPA e Coordenadora do programa e-mail: mrosario@ufpa.br.
} 
O PET Interdisciplinar Conexões de Saberes: novo diálogo entre a UFPA e as Comunidades Populares emergiu a partir das diretrizes do $\mathrm{PCS}^{4}$ e intenciona com suas atividades na escola pública, nos locais de invasão/periferia e na Universidade Federal do Pará aproxima-las mediando a construção de saberes e criando espaços de diálogo. Tendo como uma de suas ferramentas de divulgação os princípios e fundamentos teóricos metodológicos da política de ações afirmativas dentro desses espaços. O programa entende que fazer esse diálogo entre a comunidade e a UFPA oportuniza a troca de experiências além de "[...] aprofundar a formação dos jovens universitários de origem popular como pesquisadores e extensionistas, visando sua intervenção qualificada em diferentes espaços sociais [...]” (ROSÁRIO, 2013), ademais mostrar para o jovem pertencente a escola pública o Ensino Superior Público como uma possibilidade acessível e de direito de todo cidadão que termina o ensino médio público e que deseja da continuidade nos estudos.

O programa acredita que a Educação Básica é base para formação inicial das crianças e adolescentes na construção de sua cidadania, por isso, sendo direito dos mesmos. Segundo a Lei de Diretrizes e Bases da Educação Nacional (LDB) no seu $4^{\circ}$ artigo do Titulo III - Do Direito à Educação e do Dever de Educar, “O dever do Estado com a educação escolar pública será efetivado mediante a garantia de: I- educação básica obrigatória e gratuita dos 4 (quatro) aos 17 (dezessete) anos de idade [...]" (BRASIL, 96). Dessa forma, todos devem está unidos na efetivação desse direito, ou seja, governo, família e a sociedade como todo.

O programa desenvolve dois projetos na Educação Básica: O Projeto Circuito de Leitura: lendo para ser feliz, no ensino fundamental II com o intuito de ajudar na formação de educandos críticos, pois entende que a partir do gosto pela a leitura o aluno descobre um leque de possibilidades de dialogar com os assuntos inerentes a sua realidade e enxergas diferentes formas de resolver questões de seu cotidiano. Ressaltando o objetivo do projeto "No tocante à leitura, o projeto considera que é necessário associá-la ao sistema instituído e dele e com ele trabalhar a compreensão e significados à palavra, à escrita, à narração, em outras palavras à mensagem advinda dos livros" (Rosário 2013, p. 07). Dessa forma, o leitor descobre, inventa e reinventa novas possiblidades de reflexões sobre os assuntos lidos e debatidos, ou seja, através da leitura o estudante pode ser tornar um cidadão participativo de sua realidade.

\footnotetext{
${ }^{4}$ PCS- Programa Conexões de Saberes
} 
O segundo projeto desenvolvido é o Conectando Saberes com os educandos do $3^{\circ}$ do Ensino Médio, que abre rodas de discussões e diálogos sobre os temas transversais: Ações afirmativas; Juventude e Educação; Acesso e Permanência no Ensino Superior Público e Direitos Humanos. Segundo os Parâmetros Curriculares Nacionais (PCNs) os Temas Transversais “[...] têm natureza diferente das áreas convencionais. Sua complexidade faz com que nenhuma das áreas, isoladamente, seja suficiente para abordá-los. Ao contrário, a problemática dos Temas Transversais atravessa os diferentes campos do conhecimento [...]" (BRASIL, 1997, p.29). Nessa perspectiva o programa buscar trabalhar de forma transversal com esses educandos sempre fazendo um diálogo com sua realidade, pois entende que é na troca de experiências que são construídos novos saberes, como afirma Freire (1996 p. 30) "Por que não estabelecer uma intimidade entre os saberes curriculares fundamentais aos alunos e a experiência social que eles têm como indivíduos". Dessa forma, o PET contribui na construção da autonomia desse jovem ajudando-o entender seu papel de cidadão na sociedade, assim como seus direitos.

\section{MATERIAL E MÉTODOS}

O trabalho foi desenvolvido no período de Janeiro de 2010 a dezembro 2013. Seguindo os procedimentos metodológicos descritos abaixo:

$\checkmark$ Formação dos Bolsistas: Os bolsistas tiveram formação através de Oficinas de Leitura; Ações Afirmativas; Juventude e Educação; Direitos Humanos; Acesso e Permanência;

$\checkmark$ Reunião de Planejamento: Foi feita uma reunião para discutir e planejar as ações que seriam desenvolvidas na escola;

$\checkmark$ Mesas Redondas: No decorrer dos projetos foram realizadas mesas redondas que discutiam grandes filósofos para somar na formação dos bolsistas e ajudar na construção critica dos mesmos. Com o intuito de enriquecer o trabalho desenvolvido nas escolas;

$\checkmark$ Apresentação do Projeto e Planejamento: houve em cada inicio de ano uma apresentação do planejamento e projeto para o corpo técnico, docente e discente das duas escolas.

$\checkmark$ Desenvolvimento das Ações: As ações foram desenvolvidas sempre em horários vagos, onde a coordenação pedagógica incluía o circuito de leitura e 
o conectando saberes, como atividades complementares para os educandos;

$\checkmark$ Culminância e Avaliação: Ao fim de cada ano letivo é realizado uma atividade envolvendo a comunidade escolar e a comunidade ao entorno da escola, na qual os alunos apresentam as obras lidas durante a execução do projeto circuito de leitura.

\section{RESULTADOS E DISCUSSÃO}

A partir do trabalho desenvolvido percebeu-se inicialmente problemas relacionados à escola pública, pois no decorrer do projeto foram detectados problemas relacionados a material didático, merenda e infraestrutura além de greves o que não só atrapalhou o desenvolvimentos

do projeto, mas também dificultou a aprendizagem como um todo dos estudantes, principalmente dos alunos pertencentes ao terceiro ano, que estavam lutando por uma vaga no ensino superior. Isso evidencia que mesmo a Lei de Diretrizes e Bases (LDB) no seu $4^{\circ}$ artigo do Titulo III - Do Direito à Educação e do Dever de Educar, “O dever do Estado com a educação escolar pública será efetivado [...] IX- Padrões mínimos de qualidade de ensino, definidos como a variedade e quantidade mínimas, por aluno, de insumos indispensáveis ao ensino-aprendizagem” (BRASIL, 96). Entretanto, mesmo com essas dificuldades houve resultados bem relevantes no decorrer do trabalho, em relação as atividades como os alunos do terceiro ano que concorreram ao vestibular foram aprovados 10 alunos, sendo alguns em sua primeira tentativa e outros nos anos seguintes. Isso evidencia o êxito que o projeto teve, não por ser responsáveis por essas aprovações, mas sim por ter mostrado que é sim possível estudante de origem popular "furar" a barreira do vestibular e adentrar no Ensino superior gratuito e que o sistema de cotas social é um direito deles.

Outro problema identificado foi em relação aos alunos do fundamental II que no primeiro momento se mostram resistentes em participar de um projeto que envolvesse a leitura. Entretanto, com o tempo conseguimos conquistar participantes ativos do projeto e com isso conseguimos notar outro problema que cercava a maior parte dos tutorandos a dificuldade na leitura, escrita do que interpretar, o que destaca a fragilidade do sistema escola, pois a instituição tem dificuldades em alcançar dentro da educação básica o que a legislação diz, segundo a Lei de Diretrizes e Bases (LDB) 
no seu $22^{\circ}$ artigo do Titulo V, Capítulo II - Da Educação Básica, “[...] desenvolver o educando, assegurar-lhe a formação comum indispensável para o exercício o exercício da cidadania e fornecer-lhe meios para progredir no trabalho e em estudos posteriores" (BRASIL, 96). Todavia com uma intervenção pedagógica a partir de metodologias como estudo dirigido, resumos e etc. Conseguimos minimizar essa problemática na maioria dos participantes do projeto.

Em relação à coordenação de gestão e pedagógica da escola receberam a ideia do projeto de braços abertos. Com tudo tiveram algumas dificuldades em determinados turnos no decorrer desses anos, mas que foram sanados após vários replanejamentos. No que tange o corpo docente, houve uma barreira por parte da maioria dos professores o que dificultou a ideia de desenvolver um trabalho interdisciplinar e transversal tanto com os educandos do fundamental II e do ensino médio, mesmo os Parâmetros Curriculares salientando para a importância e relação dos temas transversais e a interdisciplinaridade, pois o tratamento das questões trazidas pelos Temas Transversais expõe as inter-relações entre os objetos de conhecimento, de forma que não é possível fazer um trabalho pautado na transversalidade tomando-se uma perspectiva disciplinar rígido. Sendo assim, há dialogo transversal sem a participação dos professores das diferentes disciplinas.

\section{CONCLUSÕES}

O trabalho desenvolvido na Educação Básica mostrou que ainda há uma fragilidade dentro de suas etapas de ensino com especificidades, em relação à leitura, discussões sobre cidadania, questões de trabalho transversais e sobre incentivo à entrada no ensino superior. Entretanto, foi confirmado que com um trabalho interdisciplinar e transversal envolvendo a escola e a participação do projeto, foi alcançado algumas metas, tais como a aprovação de alguns alunos em Universidades Públicas que tiveram a oportunidade de entender que com seu esforço e conhecendo o processo seletivo poderiam adentrar no Ensino Superior gratuito.

\section{REFERÊNCIAS}

BRASIL, Secretaria de Educação Fundamental. Parâmetros curriculares nacionais: apresentação dos temas transversais. Brasília: MEC/SEF, 1997. p. 29. 
FREIRE, Paulo. Pedagogia da autonomia: Saberes necessários à pratica educativa. São Paulo: Paz e Terra, 1996.

LDB - Lei de Diretrizes e Bases da Educação $\mathbf{n}^{0}$ 9.394. Disponível em: $<$ http://www.cpt.com.br/ldb/lei-de-diretrizes-e-bases-da-educacao-completainterativa-e- atualizada\#ixzz3CpFp9kFI $>$. Acesso em 09 de setembro de 2014.

PROGRAMA DE EDUCAÇÃO TUTORIAL. Manual de Orientações Básicas PET/2002 Portal MEC. Disponível em:

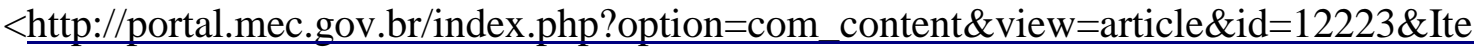
$\underline{\text { mid }=480>}$ Acesso em, 28 de maio de 2014.

ROSÁRIO, Maria J. A. Circuito de Leitura: lendo para ser feliz. Relatório Parcial de pesquisa e extensão. FAED/ICED/PROEX/UFUFPA, 2013. 